Relatório especial

\title{
Aspectos epidemiológicos da infecção por Haemophilus influenzae tipo B
}

\author{
Maria Angela Loguercio Bouskela, ${ }^{1}$ Sandra Grisi ${ }^{2}$ \\ e Ana Maria de Ulhôa Escobar ${ }^{2}$
}

RESUMO O objetivo do presente trabalho foi revisar o papel do Haemophilus influenzae tipo $b$ (Hib) como um dos patógenos mais importantes implicados em doenças infecciosas invasivas, especialmente nos 2 primeiros anos de vida. Nos países em desenvolvimento, o $\mathrm{H}$. Influenzae chega a causar $30 \%$ dos casos de pneumonia com cultura positiva e de 20 a $60 \%$ dos casos de meningite bacteriana. No presente estudo, dados epidemiológicos do Brasil foram comparados com dados internacionais obtidos em bancos de dados (Medline, 1966 a 1995; LILACS, 1982 a 1995; Thesis databank, 1980 a 1995; e Dissertation abstracts, 1988 a 1994). Analisámos o coeficiente de incidência do Hib no Brasil por estado e por faixa etária, com estratificação inclusive para o $1^{\circ}$ ano de vida. A meningite foi utilizada como marcador do coeficiente de incidência devido às dificuldades para obter material adequado para a identificação do microrganismo nos outros quadros, como pneumonia, osteomielite, epiglotite ou endocardite. Nossa análise revelou que os dados nacionais mascaram a incidência e a letalidade regionais do H. influenzae: por exemplo, em 1991, a incidência no Brasil foi de 18,4 em 100000 crianças menores de 1 ano; no mesmo período, a incidência no Distrito Federal foi de $175 \mathrm{em} 100000$ crianças entre 4 e 6 meses. Além disso, a letalidade na região Norte foi de $35 \%$ em 1987, contra $22 \%$ para o Brasil como um todo. Nosso estudo abre a discussão sobre aspectos epidemiológicos relevantes das infecções por Hib e sobre o custo-benefício da profilaxia e vacinação nas faixas etárias de maior risco.

As infecções bacterianas invasivas figuram entre as principais causas de mortalidade e morbidade na infância no mundo todo. O Haemophilus influenzae tipo b (Hib) é uma das bactérias mais importantes neste contexto. Nos países em desenvolvimento, chega a causar 30\% dos casos de pneumonia com cultura positiva e de 20 a $60 \%$ dos casos de meningite bacteriana, onde apresenta uma taxa de letalidade que atinge $40 \%$ (1). Assim, o objetivo do presente trabalho foi revisar o papel

\footnotetext{
1 Roche Químicos e Farmacêuticos S.A., Unidade de Biotecnologia de Produtos. Correspondência e pedidos de separatas devem ser enviados a esta autora no seguinte endereço: Rua Dr. Veiga Filho 371, apartamento 4 A, Higienópolis, CEP 01229-001, São Paulo, SP, Brasil. Telefone: +55-11-825-3212; 819-4862. E-mail: maria.bouskela@roche.com

2 Universidade de São Paulo (USP), Faculdade de Medicina, São Paulo, SP, Brasil.
}

do Hib como causador de doenças infecciosas nos 2 primeiros anos de vida, comparando dados do Brasil com dados internacionais.

A aderência e colonização do epitélio da nasofaringe é o primeiro passo para o desenvolvimento da doença sistêmica por Hib. Foi demonstrado que os contatos de pacientes com doença sistêmica por Hib, como familiares e freqüentadores de creches e orfanatos, apresentavam uma maior intensidade de colonização. Dentro destas famílias, foram encontradas taxas de 60 a $70 \%$ de colonização entre irmãos e $20 \%$ entre os pais $(2,3)$. Já que o desenvolvimento da infecção sistêmica por Hib exige uma grande quantidade de bacilos, os contatos acima citados estariam mais vulneráveis à doença (4-8). A colonização pode per- sistir na nasofaringe durante meses. $\mathrm{O}$ sucesso da colonização depende da cepa do Hib e das defesas locais do hospedeiro. Existem evidências de que a infecção viral pode potencializar a colonização e a doença invasiva (3).

\section{O estado de portador são e convalescente}

Michaels e Norden (9), estudando a colonização faríngea em 264 membros de 67 famílias que tiveram crianças com meningite ou epiglotite, encontraram pelo menos um portador de $\mathrm{Hib}$ em $78 \%$ das famílias. Este portador era geralmente um irmão. As crianças eram portadoras com mais freqüência do que os adultos. Dos pacientes convalescentes, $80 \%$ apresentavam colonização 
após alta hospitalar. A avaliação após 6 meses mostrou propagação desta condição. De 19 irmãos não colonizados, oito adquiriram o Hib. Após 12 meses, o número de portadores ainda aumentava e cerca de $60 \%$ das famílias ainda tinham portadores. Quando foram pesquisadas a garganta e a nasofaringe, a detecção aumentou em 33\% (9).

No Chile, Trucco et al. estudaram 31 casos de doença invasiva por $\mathrm{Hib}$ oriundos de dois hospitais de Santiago, investigando a presença de portadores entre 191 contatos intradomiciliares e observaram 6,4 portadores por caso índice (10).

No Brasil, na região da grande São Paulo, Santos estudou crianças de 6 meses a 5 anos e 11 meses em ambulatório de puericultura. Utilizou esfregaço e cultura de secreção orofaríngea em 541 crianças e demonstrou uma prevalência de $12 \%$ de portadores sadios de Hib (5).

Ainda em São Paulo, Porfírio estudou a colonização orofaríngea em três diferentes grupos: contatos domiciliares de pacientes com meningite por Hib; comunicantes domiciliares de doentes com meningite por Streptococcus pneumoniae; e famílias sem caso índice. $\mathrm{O}$ percentual de contatos de pacientes com meningite por $\mathrm{Hib}$ colonizados pelo Hib foi alto tanto em adultos quanto em crianças (10 e 48\%, respectivamente). Nos contatos domiciliares de doentes com meningite por Streptococcus spp., a colonização orofaríngea por $\mathrm{Hib}$ foi menor ( $6 \%$ nas crianças). Em famílias sem caso índice, a colonização foi elevada tanto nos adultos quanto nas crianças, respectivamente 15 e 33\% (11). O percentual de colonização encontrado no estudo acima é o maior dos estudos brasileiros em portadores sãos e encontra poucos estudos comparáveis na literatura internacional (9).

No Hospital Emílio Ribas, de São Paulo, especializado no tratamento de doenças infecto-contagiosas, a presença de portadores convalescentes de meningite por $\mathrm{Hib}$ e meningococo após o tratamento com antimicrobianos específicos foi avaliada em 122 pacientes: destes, $2 \%$ foram identificados como portadores de Hib (12).

Nos Estados Unidos, a vacinação em massa contra o Hib causou forte im- pacto nas taxas de portadores. A incidência diminuiu inclusive nos menores de 15 meses, que de início não receberam a vacina (13). Tal observação deve ser decorrência da colonização por aumento da imunidade local e redução da transmissão. Ainda nos Estados Unidos, a incidência em crianças com menos de 5 anos caiu 95\% em todo o país, após o uso da vacina (14). Na Finlândia, em portadores de até 3 anos, a incidência era de 4\% em 1987 e 1988 (antes da vacinação em massa) e 0\% no mesmo grupo em 1989 e 1990, após vacinação em massa. Por outro lado, trabalho publicado em Valência, Espanha, verificou que o Hib continua sendo uma causa freqüente de meningite, não obstante o fato de que um terço das crianças são vacinadas (15).

\section{Incidência do Hib}

Entre as diversas manifestações de doença invasiva por Hib, a meningite serve como um marcador da incidência, já que é difícil a identificação do organismo causador em outros tipos de infecção, como a pneumonia. A tabela 1

TABELA 1. Incidência da meningite por Haemophilus influenzae tipo $b$ em diferentes populações

\begin{tabular}{|c|c|}
\hline População, período e faixa etária & $\begin{array}{l}\text { Número de casos } \\
\text { (100 } 000 \text { habitantes) }\end{array}$ \\
\hline \multicolumn{2}{|l|}{ Brasil, 1987 a 1991} \\
\hline$<1$ ano & 18,4 \\
\hline$<5$ anos & 5 \\
\hline \multicolumn{2}{|l|}{ Gâmbia, 1985 a 1987} \\
\hline$<1$ ano & 297 \\
\hline$<5$ anos & $60^{\mathrm{a}}$ \\
\hline \multicolumn{2}{|l|}{ Dacar, Senegal, 1970 a 1979} \\
\hline$<1$ ano & 132 \\
\hline$<5$ anos & 51 \\
\hline \multicolumn{2}{|l|}{ Países escandinavos, 1974 a 1984} \\
\hline$<1$ ano & 27 a 59 \\
\hline$<5$ anos & 16 a 28 \\
\hline \multicolumn{2}{|l|}{ Estados Unidos } \\
\hline \multicolumn{2}{|l|}{ Navajos, 1968 a 1973} \\
\hline$<1$ ano & 550 \\
\hline$<$ anos & 173 \\
\hline \multicolumn{2}{|l|}{ Apaches, 1973 a 1981} \\
\hline$<1$ ano & 1169 \\
\hline$<5$ anos & 264 \\
\hline \multicolumn{2}{|l|}{ Nativos do Alasca } \\
\hline$<1$ ano, 1971 a 1974 & 871 a 2323 \\
\hline$<5$ anos, 1980 a 1982 & 282 a 474 \\
\hline \multicolumn{2}{|c|}{ Não nativos do Alasca, 1980 a 1982} \\
\hline$<1$ ano & 155 \\
\hline$<5$ anos & 69 \\
\hline \multicolumn{2}{|l|}{ Austrália, 1985 a 1988} \\
\hline \multicolumn{2}{|l|}{ Aborígenes } \\
\hline$<5$ anos & 159 \\
\hline \multicolumn{2}{|l|}{ Não aborígenes } \\
\hline$<5$ anos & 53 \\
\hline \multicolumn{2}{|l|}{ Israel, 1981 a 1985} \\
\hline \multicolumn{2}{|l|}{ Beduínos } \\
\hline$<1$ ano & 50 a 100 \\
\hline$<5$ anos & 28 \\
\hline \multicolumn{2}{|l|}{ Judeus } \\
\hline$<1$ ano & 40 a 75 \\
\hline$<5$ anos & 18 \\
\hline
\end{tabular}


apresenta dados sobre a incidência da meningite por Hib em diversos países.

Geralmente, uma maior incidência correlaciona-se com um grupo de faixa etária menor. As diferenças podem ser explicadas por fatores que facilitam a exposição, como convivência em ambientes aglomerados e outras variáveis relacionadas a fatores socioeconômicos. Fatores genéticos podem estar envolvidos (17-20).

No Brasil, os dados disponíveis são do Centro Nacional de Epidemiologia (CENEPI) do Ministério da Saúde, para 1987 a 1991, e mostram notificação de 128244 casos de meningites das mais diversas etiologias. Analisando-se apenas os menores de 4 anos, em série histórica (comparando Hib, bacilos gramnegativos, doença meningocócica e meningites bacterianas inespecíficas), observa-se um aumento na incidência do Hib a partir de 1987. Este aumento deve decorrer de uma melhora na qualidade do diagnóstico. $\mathrm{O}$ coeficiente de incidência nas diversas etiologias, de 1987 a 1991, está representado na figura 1. O Hib foi o agente atribuído a $5 \%$ do total de casos. Comparando-se as etiologias Hib, Neisseria meningitidis e $S$. pneumoniae, agentes responsáveis por praticamente todos os casos de meningite com agente identificado, tem-se no Hib o mais freqüente causador da doença no $1^{\circ}$ ano de vida (incluindo-se os anos em que a doença meningocócica ocorreu de forma epidêmica). Como o Hib é um bacilo gram-negativo em sua forma morfotintorial, no conjunto das meningites causadas por bacilos gramnegativos, um percentual deve, provavelmente, corresponder ao Hib.

Para a análise da incidência de meningite por Hib, foram excluídos os casos com diagnósticos presuntivos (bacterioscopia), restando 6342 casos diagnosticados através de cultura, contra-imunoeletroforese ou aglutinação pelo látex. Cerca de 50\% ocorreram em menores de 1 ano e $90 \%$ em crianças com até 4 anos.

Os achados sugerem uma incidência de 50 por 100000 habitantes nos menores de 1 ano e, nas crianças de 1 a 4 anos, de 10 em 100000 habitantes. A figura 2 mostra a incidência de me- ningite por Hib nas diferentes regiões brasileiras.

No presente estudo, os dados para cada estado foram estratificados por faixa etária, inclusive dentro do $1^{\circ}$ ano de vida. A figura 3 mostra a incidência isolada para alguns estados brasileiros. A comparação entre estados isolados sugere diferenças significativas na qualidade do diagnóstico e a notificação. Por exemplo, o diagnóstico e a notificação parecem ser mais eficientes

FIGURA 1. Incidência de meningite por diversas causas em crianças menores de 4 anos, Brasil, 1987 a 1991

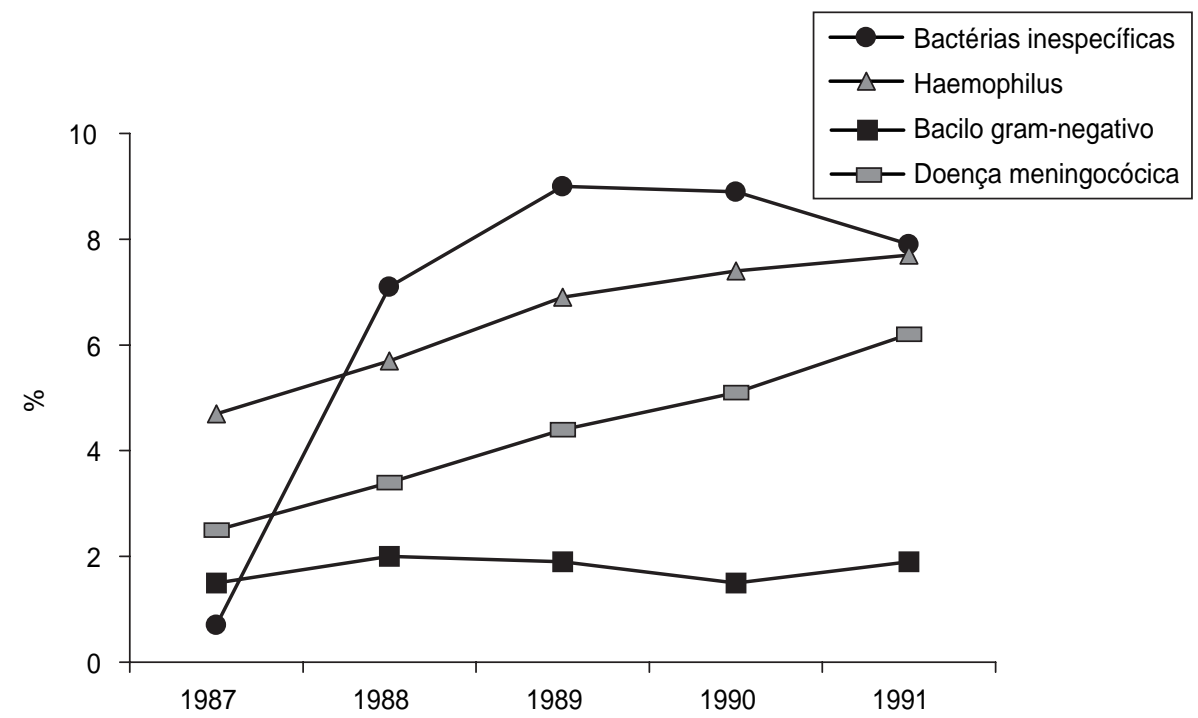

Fonte: Centro de Doenças Infecciosas (CDI)/Centro Nacional de Epidemiologia (CENEPI)/Fundação Nacional de Saúde (FNS), 1993.

FIGURA 2. Incidência de meningite por Haemophilus influenzae nas diversas regiões do Brasil por faixa etária, 1991

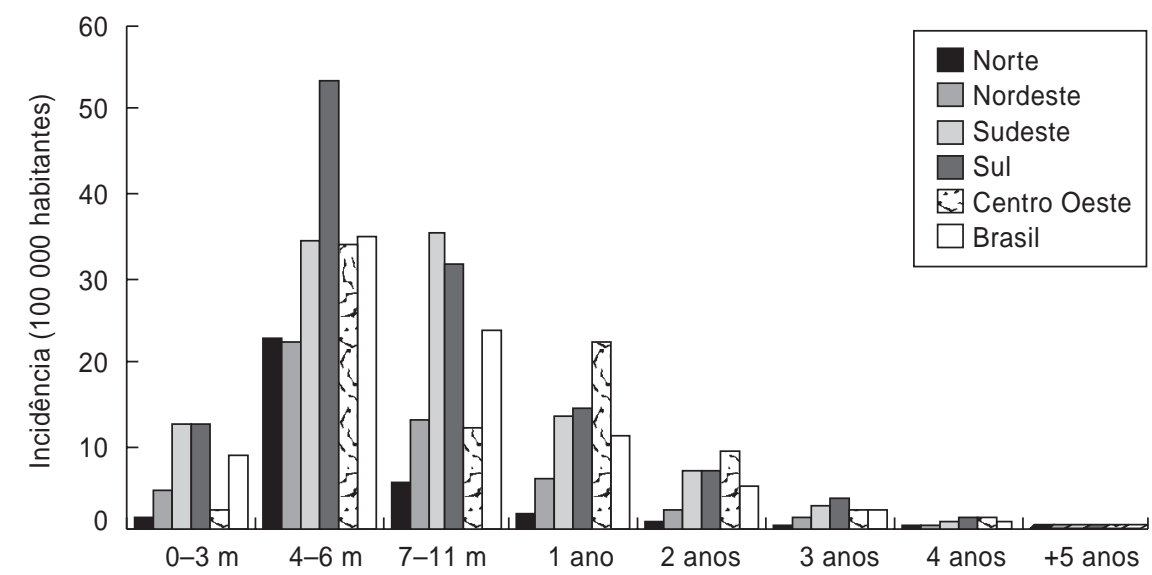

Fonte: Centro de Doenças Infecciosas (CDI)/Centro Nacional de Epidemiologia (CENEPI)/Fundação Nacional de Saúde (FNS), 1993. 
FIGURA 3. Brasil e estados com maior incidência de meningite por Haemophilus influenzae segundo a faixa etária, 1991

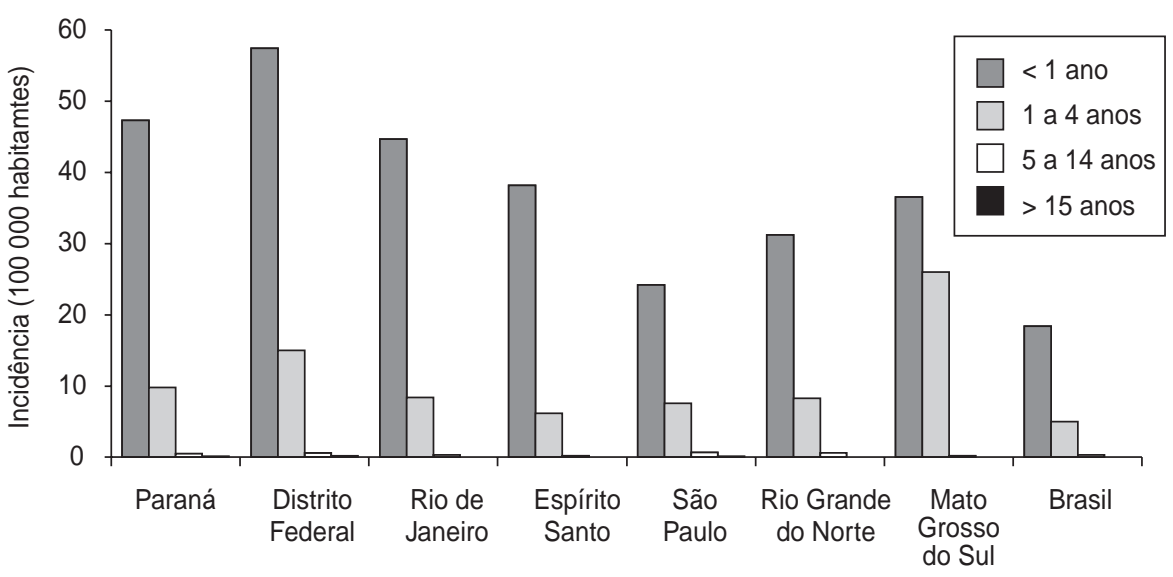

Fonte: Centro de Doenças Infecciosas (CDI)/Centro Nacional de Epidemiologia (CENEPI)/Fundação Nacional de Saúde (FNS), 1993

no Distrito Federal, Paraná e Rio de Janeiro.

\section{Fatores de risco para infecção por Hib}

A prevalência de fatores de risco em diferentes populações e grupos etários pode ser decisiva, determinando o impacto epidemiológico e explicando as variações na incidência e distribuição etária entre as populações. Os principais fatores de risco para infecção por Hib são a idade, fatores socioeconômicos (que se sobrepõem aos riscos genéticos), freqüentar ambientes como creches, presença de infecções associadas, ausência de aleitamento materno e fumo passivo.

De todos os fatores de risco, a idade é o mais importante. Na maioria dos estudos, cerca de $95 \%$ dos casos acontecem em crianças com menos de 2 anos (21-23). No Brasil, segundo dados do CENEPI, cerca de $70 \%$ dos casos ocorrem nesta faixa etária (24).

Os fatores de risco socioeconômicos para doença primária invasiva por $\mathrm{Hib}$ compreendem variáveis que aumentam a exposição (freqüentar creche, presença de irmãos, ambiente familiar aglomerado) e variáveis que aumen- tam a suscetibilidade individual (desmame precoce, pais fumantes e infecções freqüentes). No Brasil, um estudo sobre meningites virais e bacterianas no Rio de Janeiro, no segundo semestre de 1978, revelou um risco de adquirir meningite por Hib 2,8 vezes maior para os moradores de favela (25).

A dispersão de gotículas, seguindose a colonização, é a maneira mais comum de transmissão da doença invasiva por Hib. O contato com objetos, como brinquedos contaminados levados à boca, também tem sido descrito como importante fator de risco (26). As secreções nasais de portadores têm concentração maior da bactéria do que a secreção orofaríngea. O Hib pode sobreviver em objetos como toalhas, fraldas ou bichos de pelúcia por até 48 horas (26).

Alguns autores observaram risco 12,3 vezes maior para crianças menores de 1 ano que freqüentam creches; 7,2 vezes maior para crianças de 1 a 2 anos; e 3,8 vezes maior para crianças de 2 a 3 anos (27). É descrito um risco maior diretamente proporcional ao período de permanência na creche e ao número de crianças na classe. No Brasil, a questão da incidência dependente da permanência em creches ainda precisa ser aprofundada. Um estudo mostra que ter irmãos entre 6 e 10 anos ou membro da família freqüentando ensino fundamental (primeiros 8 anos na escola) aumenta o risco (7).

Em termos de infecções associadas, a concomitância de focos infecciosos foi encontrada em $35 \%$ dos pacientes em um estudo realizado no Brasil principalmente otite média aguda e pneumonia (28). As infecções virais ou por Mycoplasma pneumoniae foram sugeridas como comumente associadas ao desencadeamento de meningite por Hib. Estudos experimentais em animais usando o vírus influenza $\mathrm{A}$, o vírus sincicial respiratório e os virus parainfluenza tipos 1 e 2 sustentam esta hipótese (29-33).

Um importante fator protetor descrito para a doença invasiva por Hib é o aleitamento materno. Na Finlândia, a duração do aleitamento materno é de pelo menos 6 meses e tem sido considerada protetora. É possível que o mecanismo de proteção envolva a presença de anticorpos anticapsulares no leite humano ou um aumento da resposta imune ao Hib entre as crianças amamentadas. A ação da imunoglobulina A (IgA) secretória na proteção contra as infecções por poliovírus, rubéola, influenza, rinovírus e rotavírus tem sido demonstrada. Estudos mostram que a IgA secretória dificulta a aderência do microrganismo na superfície da mucosa, reduzindo a colonização. É possível que a $\operatorname{IgA}$ secretora, banhando a orofaringe durante a amamentação, interaja com as mucinas e o glicocálix na nasofaringe, exercendo seu efeito protetor. Não temos dados brasileiros analisando comparativamente o efeito protetor da amamentação na colonização ou incidência da doença invasiva em crianças no $1^{\circ}$ ano de vida.

O fumo passivo (exposição à fumaça do tabaco) pode causar danos à mucosa da árvore respiratória, facilitando a aderência e invasão por Hib. Entre as populações nativas americanas, por exemplo, os navajos, que tradicionalmente usam fogo para aquecer suas casas, este fator está sendo cuidadosamente avaliado. As infecções respiratórias virais somam-se à maior predisposição, aumentando a suscetibilidade à infecção por Hib. 
FIGURA 4. Letalidade da meningite por Haemophilus influenzae em diferentes populações

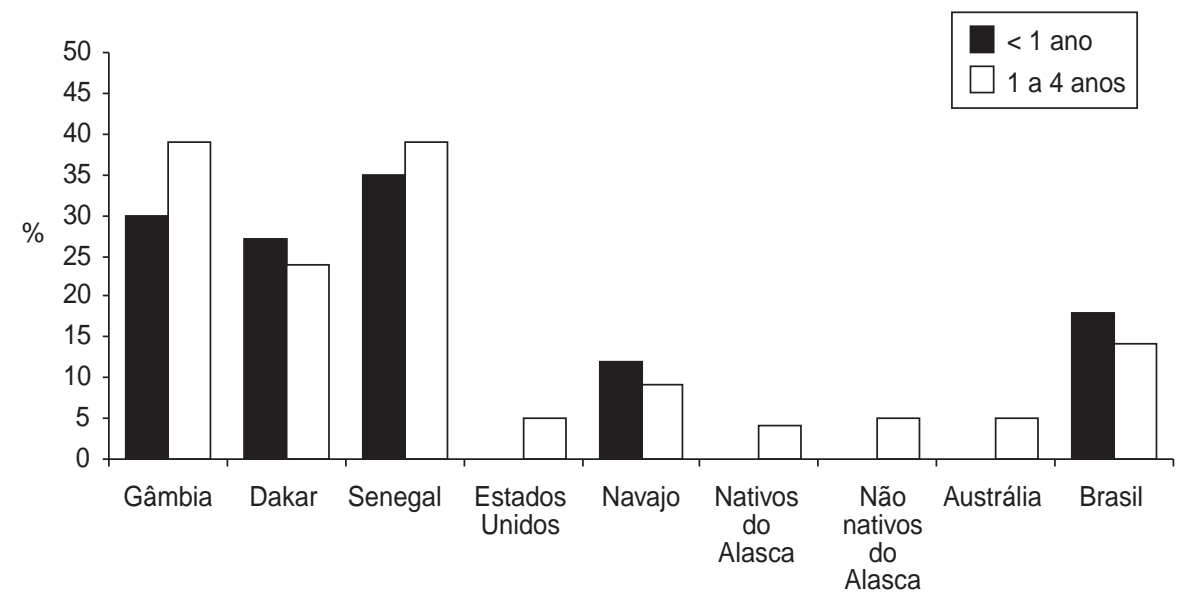

Fonte: Funkhouser et al. (1). Dados brasileiros do Centro de Doenças Infecciosas (CDI)/Centro Nacional de Epidemiologia (CENEPI)/Fundação Nacional de Saúde (FNS), 1993.

\section{Casos secundários de meningite por Hib}

Define-se como caso secundário de meningite aquele que ocorre no mesmo ambiente, em tempo maior do que 24 horas e menor do que 31 dias após o aparecimento da doença no caso índice. Casos que ocorrem nas primeiras 24 horas após a ocorrência do caso índice são chamados co-primários (3).

Os determinantes do risco de casos secundários são a natureza da exposição e a idade dos contatos. O risco é maior na $1^{a}$ semana após o aparecimento da doença no caso índice e diminui após este período. De cada oito casos secundários, seis aparecem nos primeiros 4 dias de doença do caso índice. Poucos são doentes co-primários. Observa-se que o período de risco para infecções secundárias é maior em crianças dos centros de cuidados infantis do que nos contatos domiciliares $(8,34,35)$.

Parece, no entanto, que o caso índice, por si, não põe os contatos em risco, mas sim que o paciente índice serve como um marcador de que há uma alta prevalência de colonização por Hib no grupo ao qual ele pertence. Embora comumente se assuma que o caso índice transmita a doença ao caso secundário, pode ser que ambos te- nham adquirido a doença por exposição comum a um ou mais portadores.

\section{Mortalidade e letalidade do Hib}

Os dados referentes à mortalidade por Hib são escassos na literatura. A letalidade, porém, é freqüentemente citada, variando entre 15 e $40 \%$ nos países em desenvolvimento, enquanto que nos Estados Unidos, Alasca e Europa, fica em torno de 5\%. Em Israel, a letalidade referida é de $2 \%$ e na África, entre 20 e $40 \%(18,23$, 36-41) (figura 4). No Chile, no período de 1985 a 1987, foi encontrada uma letalidade de $16 \%$ para a meningite e $8 \%$ para outras doenças invasivas na população abaixo de 5 anos de idade (19).

\section{Mortalidade e letalidade do Hib no Brasil}

Tendo como fonte o CENEPI (dados de 1987 a 1991), encontramos coeficientes de mortalidade por meningite por Haemophilus, na faixa etária menor de 1 ano de idade, variando entre 0,1 em 1987 a 0,2 em 1991, e na faixa etária de 1 a 4 anos, variando de 0,3 a 0,7 . Nos maiores de 5 anos, o coeficiente foi 0 (zero), exceto em 1989, quando a faixa etária de 5 a 14 anos apresentou coeficiente de 0,1 .

Com relação à letalidade, encontramos, considerando-se todas as faixas etárias em conjunto, uma variação de 5 a $20 \%$. Estratificando-se a letalidade em faixas etárias, observa-se que, nos menores de 1 ano, ela supera a das outras faixas etárias, mantendo-se próxima a $20 \%$ (figura 5).

Se regionalizarmos a análise, observamos que a letalidade na região Norte, em 1987, alcançou 35\%, índice bem acima das outras regiões brasileiras no mesmo ano. Nos anos subseqüentes, houve redução destes índices.

\section{DISCUSSÃO}

É certa a importância do Hib como causa de morbidade e mortalidade infantil no mundo. No Brasil, o sistema de notificação é incompleto e a subnotificação subestima a magnitude da infecção causada pelo Hib. Dentre as doenças infecciosas invasivas causadas pelo Hib, a meningite é a de diagnóstico clínico e comprovação etiológica mais direta. Dessa forma, somente dados sobre meningite estão disponíveis no Brasil. Ainda assim, em algumas regiões há dificuldade para identificar a espécie e o tipo de Hib, já que o diagnóstico de meningite por Hib depende da obtenção de hemoculturas, detecção de antígeno no líquido cefalorraquidiano (LCR), soro ou urina ou cultura de líquor. Neste sentido, existe a possibilidade de que a casuística classificada como meningite por bacilo gram-negativo seja, em grande parte, meningite por Hib. O conjunto destas considerações deve explicar a incidência menor de meningite por Hib no Brasil do que aquela observada em alguns países desenvolvidos (tabela 1).

A alta incidência de pneumonia por Hib encontrada nos raros estudos em países em desenvolvimento e em alguns países desenvolvidos foi atribuída ao grande número de infecções virais, desnutrição, colonização precoce e altas taxas de portadores. No Brasil não existem estudos com enfoque epidemiológico em pneumonia. 
FIGURA 5. Letalidade da meningite por Haemophilus influenzae conforme faixa etária, Brasil, 1987 a 1991

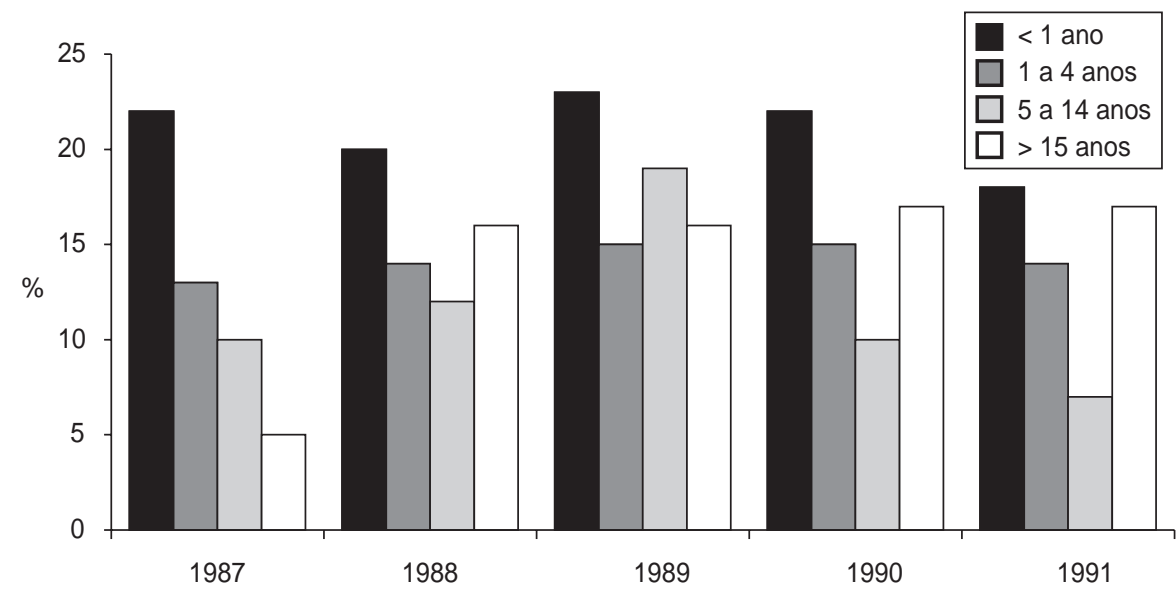

Fonte: Centro de Doenças Infecciosas (CDI)/Centro Nacional de Epidemiologia (CENEPI)/Fundação Nacional de Saúde (FNS), 1993.

O aspecto de colonização em portadores sadios, contatos e convalescentes mostra que nossas taxas de colonização nos contatos e portadores sadios estão acima da maioria das taxas relatadas na literatura.

$O$ percentual de incidência nos primeiros 6 meses de vida não chegou a $5 \%$ na Finlândia, contra 18\% nos Estados Unidos, $30 \%$ entre os nativos do Alasca e $24 \%$ no Brasil. Este dado brasileiro mostra que a doença incide em idade precoce no país, apesar de o Brasil não estar entre os países de maiores coeficientes de incidência. No Distrito Federal, entre 1987 e 1991, a incidência em crianças menores de 1 ano foi de 54 em 100000 habitantes, ou 12 em 100000 nos menores de 5 anos. Nos países nórdicos, a faixa etária acometida desloca-se para idades mais avançadas e a incidência é menor.

Analisando-se separadamente as diferentes regiões brasileiras, encontramos, na região Sul e Sudeste, incidência de 10 em 100000 na faixa etária de 0 a 3 meses e 53 e 34 em 100000 aos 4 e 6 meses, respectivamente. Dos 7 aos 11 meses, as regiões Sudeste e Sul têm coeficientes de, respectivamente, 35 e 31 , os maiores do país. A região CentroOeste tem o maior coeficiente dos 12 aos 23 meses, sendo, pois, a região onde a incidência se desloca para as faixas etárias maiores. A incidência nos menores de 5 anos no Brasil vem aumentando, tendo passado de 13,4 para 18,4 em menores de 1 ano e de 2,8 para 5,0 na faixa etária de 1 a 4 anos, no período de 1987 a 1991. Considerando-se todas as crianças com idade inferior a 4 anos, o coeficiente variou de 4,7 em 1987 a 7,7 em 1991.

O Brasil, analisado como um todo, está entre os países de menor incidência, conforme dados da literatura mundial. A estratificação por faixa etária indica que a incidência no Brasil segue a tendência mundial: $90 \%$ dos casos são crianças menores de 5 anos e $50 \%$, crianças de até 1 ano. Chama a atenção a análise isolada de alguns estados por faixa etária no $1^{\circ}$ ano de vida. Como exemplo, citamos o Distrito Federal, com incidência de 175 em 100000 crianças; o Paraná, incidência de 98; o Espírito Santo, com 55; e o Amapá, com incidência de 51 casos em 100000 crianças entre 4 e 6 meses no ano de 1991. Embora não tenhamos encontrado um paralelo na literatura mundial de análise por estas faixas etárias, entendemos como preocupantes estes dados. Considerando-se todo o $1^{\circ}$ ano de vida nestes mesmos estados, esta observação acaba sendo mascarada, porque a incidência diminui para 57,4 ; 47,4; 38,2; e 21,7 por 100000 crianças.
De 1987 a 1991, em todas as regiões brasileiras, o Hib foi o principal agente das meningites bacterianas em menores de 5 anos, sendo responsável por $40 \%$ dos casos. Nas crianças acima de 5 anos, figura como o terceiro agente etiológico em ordem de importância.

Considerando os custos hospitalares e seqüelas, fica claro o custo-benefício da inclusão da vacina anti-Hib no calendário vacinal. Benefício adicional à imunização é a redução do número de portadores, aumentando o impacto e diminuindo a disseminação do Hib.

A mortalidade da meningite por Haemophilus, no Brasil, foi crescente de 1987 a 1991, chegando a 0,7. Quanto à letalidade no período considerado pelo estudo, observamos valores em torno de $20 \%$ em menores de 1 ano, $12 \%$ entre 1 e 4 anos, $10 \%$ entre 5 e 14 anos e $15 \%$ em adultos.

Até 1989 , as regiões Norte e Nordeste apresentavam taxas de letalidade maiores do que as outras regiões. A partir de 1990, houve uma homogeneização. Em 1992, último ano avaliável pelos dados do CENEPI, o quadro mostra pequenas variações entre as diversas regiões.

Analisando os dados nacionais, observamos que a taxa de letalidade é alta em nosso meio, assim como a incidência em alguns estados da federação, além da falta de acuidade na identificação do agente etiológico em algumas regiões. Parece-nos lógica a instituição da vacinação anti-Hib no Brasil acompanhada de estudos epidemiológicos mais rigorosos. Os altos coeficientes encontrados em faixas etárias como a de 4 a 6 meses (175, 98 e 70 em 100000 no Distrito Federal, Paraná e Rio Grande do Norte), combinados às taxas de letalidade e ao desconhecido aspecto seqüelas, compõem um quadro preocupante, que requer medidas rápidas e eficazes de controle.

\section{CONSIDERAÇÕES FINAIS}

O Hib é um agente de grande importância na morbi-mortalidade infantil. Das doenças invasivas por ele causadas, a meningite é o marcador epidemiológico devido às dificuldades de 
isolamento do agente nos outros tipos de infecção. A taxa de colonização pelo Hib na comunidade e os fatores de risco preponderantes devem ser conhecidos para que medidas de impacto epidemiológico possam ser tomadas.

O Brasil apresenta um quadro epidemiológico parecido com o de países em desenvolvimento, com alta incidência em crianças mais jovens e letalidade acima de $15 \%$ em praticamente todas as faixas etárias. Os dados le- vantados apontam para a necessidade da determinação dos fatores de risco em nosso meio. Parece clara, também, a necessidade de capacitação dos laboratórios de microbiologia para o domínio da técnica de isolamento do Hib. A partir de 1999, foi criada uma normatização para a notificação das doenças invasivas pelo Hib. A educação médica continuada pode contribuir para que o diagnóstico seja cada vez mais rápido, o que poderá refletir positivamente na diminuição da taxa de letalidade.

Os países que já instituíram a vacinação tiveram seu quadro epidemiológico alterado, com diminuição das taxas de colonização mesmo nas crianças não vacinadas. No Brasil, a vacinação contra o Hib foi incluída no calendário vacinal a partir de 1999, sendo recomendadas três doses no $1^{\circ}$ ano de vida (2, 4 e 6 meses) e uma dose em crianças de 1 a 5 anos de idade.

\section{REFERÊNCIAS}

1. Funkhouser A, Steinhoff CM, Ward J. Haemophilus influenzae disease and immunization in developing countries. Rev Infect Dis 1991; 13(6):S542-S554.

2. Wenger JD; Ward JI; Broome CV. Prevention of Haemophilus influenzae type b disease: vaccines and passive prophylaxis. Curr Clin Top Infect Dis 1989;10:306-339.

3. Shapiro ED, Ward JI. The epidemiology and prevention of disease caused by Haemophilus influenzae type b. Epidemiol Rev 1991;13: 113-142.

4. Moxon ER, Smith AL, Averill DR, Smith DH. Haemophilus influenzae meningitis in infant rats after intranasal inoculation. J Infect Dis 1974;129(2):154-167.

5. Santos WP. Estudo da prevalência de portadores sadios de Haemophilus influenzae tipo b e sua importância epidemiológica [dissertação de mestrado]. São Paulo: Escola Paulista de Medicina; 1987.

6. Michaels RH, Stonebraker FE. Use of antiserum agar for detection of Haemophilus influenzae type $\mathrm{b}$ in the pharynx. Pediatr Res 1975;9(5):513-516.

7. Istre GR, Conner JS, Broome CV, Hightower A, Hopkins RS. Risk factors for primary invasive $H$. influenzae disease: increased risk from day care attendance in school age household members. J Pediatr 1985;106(2):190-195.

8. Fleming DW, Leibenhaut MH, Albanes D, Cochi SL, Hightower AW, Makintubee S, Helgerson SD, Broome CV. Secondary Haemophilus type $b$ in day care facilities: risk factors and prevention. JAMA 1985;254(4):509-514.

9. Michaels RH, Norden CW. Pharyngeal colonization with Haemophilus influenzae type b: a longitudinal study of families with a child with meningitis or epiglottitis due to $H$. influenzae type B. J Infect Dis 1977;136(2):222228.

10. Trucco AO, Prado JV, Cofré G, Vergara J, Siri MT, Ledermann W, et al. Difusion de $H$. influenzae tipo b en contactos intrafamiliares de niños con infecciones sistémicas por este agente. Rev Chil Pediatr 1988;59(5):306-311.

11. Porfírio FMV. Estudo da colonização orofaríngea pelo Haemophilus influenzae tipo b (Hib) e seus biotipos nos contatos domicide Medicina; 1994. liares de pacientes com meningite [dissertação de mestrado]. São Paulo: Escola Paulista

12. Schmidt C. Estudo de 122 crianças internadas com meningites bacterianas devidas ao Haemophilus influenzae tipo b e Neisseria meningitidis: Avaliação do estado de portador convalescente [tese de doutorado]. São Paulo: Escola Paulista de Medicina; 1992.

13. Mohle-Boetani JC, Ajello G, Breneman E, Deaver KA, Harvey C, Plikaytis BD, et al. Carriage of Haemophilus influenzae type $\mathrm{b}$ in children after widespread vaccination with conjugate Haemophilus influenzae type $\mathrm{b}$ vaccines. Pediatr Infect Dis J 1993;12(7):569-593.

14. MMWR. Haemophilus influenzae invasive disease among children aged $<5$ years - California, 1990-1996. MMWR Morb Mortal Wkly Rep 1998;47(35):737-740.

15. Morant A, Díez J, Gimeno C, de la Muela N, Pereiró I, Brines J. Epidemiology of Haemophilus influenzae type b, Neisseria meningitidis and Streptococcus pneumoniae in children in the Valencia community, Spain. Acute diseases study group. Rev Neurol 1998;26(149):34-37.

16. Mäkelä HP, Takala KA, Peltola H, Eskola J. Epidemiology of invasive Haemophilus influenzae type b disease. J Infect Dis 1992;165(Suppl 1):S2-S6.

17. Granoff DM, Munson Jr RS. Prospects for prevention of $H$. influenzae type $\mathrm{b}$ disease by immunization. J Infect Dis 1986; 153(3):448-461.

18. Cochi SL, Ward JI. Haemophilus influenzae type b. Em: Evan AS, Bracchan PS, eds. Bacterial infections in humans: epidemiology and control. 2a ed. New York: Plenum Medical Books; 1990.

19. Ferreccio C, Ortiz E, Astroza L, Rivera C, Clemens J, Levine MM. A population-based retrospective assessment of the disease burden resulting from invasive Haemophilus influenzae in infants and young children in Santiago. Chil Pediatr Infect Dis J 1990;9(7): 488-494.

20. Lagos R, Avendano A, Horwitz I, Musser JM, Hoiseth SK, Maneval DR Jr, et al. Molecular epidemiology of Haemophilus influenzae within families in Santiago, Chile. J Infect Dis 1991; 164(6):1149-1153.
21. Ward JI, Lum MK, Hall DB, Silimperi DR, Bender TR. Invasive Haemophilus influenzae type $\mathrm{b}$ disease in Alaska: background epidemiology for a vaccine efficacy trial. J Infect Dis 1986;153(1):17-26.

22. Takala AK. Epidemiologic characteristics and risk factors for invasive Haemophilus influenzae type $b$ disease in a population with high vaccine efficacy. Pediatr Infect Dis J 1989;8(6): 343-346.

23. Murphy TV, Clements JF, Petroni M, Coury S, Stetler L. Haemophilus influenzae type $\mathrm{b}$ in respiratory secretions. Pediatr Infect Dis J 1989; 8(3):148-151.

24. Brasil. Guia de vigilância epidemiológica. Brasília: Centro Nacional de Epidemiologia; 1999.

25. Nery-Guimarães R, Bittencourt LCM, Pastor MVA. Meningites virais e bacterianas no município do Rio de Janeiro (Brasil): algumas considerações sobre o sistema de informações em saúde e sobre a distribuição da doença no espaço urbano. Rev Saude Publica 1981;15(4): 379-394.

26. Peltola H, Rod TO, Jondosttir K, Böttiger M, Coolidge JA. Life-threatening Haemophilus influenzae infections in Scandinavia: a fivecountry analysis of the incidence and the main clinical and bacteriological characteristics. Rev Infect Dis 1990;12(4):708-715.

27. Redmond SR, Pichichero ME. Haemophilus influenzae type b disease: an epidemiologic study with special reference to day care centers. JAMA 1984;252(18):2581-2584.

28. Freire MBH. Meningite por Haemophilus influenzae: análise de aspectos epidemiológicos, clínicos, laboratoriais e terapêuticos [tese de mestrado]. Belo Horizonte: Faculdade de Medicina, Universidade Federal de Minas Gerais; 1986.

29. Krasinski K, Nelson JD. Viral-bacterial interactions in experimental meningitis. Em: American Society for Microbiology. Interscience conference on antimicrobial agents and chemotherapy; 1980; New Orleans. Washington DC: American Society for Microbiology; 1980.

30. Kaplan SL, Taber LH, Frank AL, Feijin RD. Nasopharyngeal viral isolates in children with Haemophilus influenzae type $b$ meningitis. J Pediatr 1981;99(4):591-593. 
31. Myerowitz RL, Michaels RH. Mechanism of potentiation of experimental Haemophilus influenzae type $\mathrm{b}$ disease in infant rats by influenza A virus. Lab Invest 1981;44(5): 434-441.

32. Krasinski K, Nelson JD, Butler U. Possible association of Mycoplasma and viral respiratory infections with bacterial meningitis. Am J Epidemiol 1987;125(3):499-508.

33. Rosenthal J, Dagan R, Press J, Sofer S. Differences in the epidemiology of childhood community-acquired bacterial meningitis between two ethnic populations cohabiting in one geographic area. Pediatr Infect Dis 1988; 7(9):630-633.

34. Granoff DM, Gilsdorf J, Gessert C, Lowe L. Haemophilus Influenzae type $\mathrm{b}$ in day care center, relationship of nasopharyngeal carriage to development of anticapsular antibody. Pediatrics 1980;65(1):65-67.
35. Makintubee S, Istre GR, Ward JI. Transmission of invasive Haemophilus influenzae type $b$ disease in day care settings. J Pediatr 1987; 111(2):180-186.

36. Cadoz M, Denis F, Mar ID. Etude epidemiologique des cas de meningites purulentes hospitalises a Dakar pendant la decennie 1970-1979. Bull World Health Organ 1981; 59(4):575-584.

37. Gratten M, Barker J, Shann F, Gerega G, Montgomery J, Kajoi M, et al. The aetiology of purulent meningitis in highland children: a bacteriological study. P N G Med J 1985; 28(4):233-240.

38. Nottidge VA. Haemophilus influenzae meningitis: a 5-year study in Ibadan, Nigeria. J Infect 1985;11(2):109-117.

39. Tudor-Williams G, Frankland J, Isaacs D, Mayon-White TT, MacFarlane JA, Slack MP, et al. Haemophilus influenzae type $\mathrm{b}$ disease in the Oxford region. Arch Dis Child 1989;64(4): 517-519.

40. Bijlmer HA, van Alphen L, Greenwood BM, Brown J, Schneider G, Hughes A, et al. The epidemiology of Haemophilus influenzae meningitis in children under five years of age in Gambia, West Africa. J Infect Dis 1990;161(6): 1210-1215.

41. Dagan R, Isaachson I, Lang R, Karpuch J, Block C, Amir J. Epidemiology of pediatric meningitis caused by Haemophilus influenzae type b: Streptococcus pneumoniae, and Neisseria meningitidis in Israel: a 3-year, nationwide prospective study. J Infect Dis 1994;169(4):912-916.

Manuscrito recebido em 2 de março de 1999. Aceito em versão revisada em 8 de fevereiro de 2000.

ABSTRACT This paper reviews the role of Haemophilus influenzae type $\mathrm{b}(\mathrm{Hib})$ as one of the most important pathogens causing invasive infectious diseases, especially in the first 2 years of life. In developing countries $H$. influenzae is responsible for $30 \%$ of all pneumonia cases with positive cultures and for $20 \%$ to $60 \%$ of all bacterial meningitis cases. In this study we compared Brazilian and international epidemiologic data obtained from several bibliographic databases (MEDLINE, 1966 to 1995; LILACS, 1982 to 1995; Thesis Databank, 1980 to 1995; and Dissertation Abstracts, 1988 to 1994). The incidence of Hib infection in Brazil was analyzed for individual states and for different ages, including within the first year of life. Meningitis cases were used as an incidence marker because of the difficulty in identifying the causative organism in such other infections as pneumonia, osteomyelitis, epiglottitis, cellulitis, and endocarditis. Our analysis showed that the nationwide Brazilian data masked the regional incidence and lethality of $H$. influenzae. For example, in 1991 the national incidence was 18.4 per 100000 children under 1 year of age. In the same period, the Federal District had an incidence of 175 per 100000 among children between 4 and 6 months of age. Similarly, the North of Brazil had a 35\% case fatality rate in 1987, whereas the rate was $22 \%$ for Brazil as a whole. This study raises issues concerning the relevant epidemiologic factors associated with Hib infection and the costs and benefits of prophylaxis and vaccination in the age groups most at risk. 